\title{
Cilostazol to Overcome High On-Treatment Platelet Reactivity in Korean Patients Treated With Clopidogrel and Calcium-Channel Blocker
}

\author{
Young-Hoon Jeong, MD, PhD; Udaya S. Tantry, PhD; Kevin P. Bliden, BSc; Paul A. Gurbel, MD
}

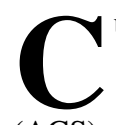

urrent oral antiplatelet therapy mainly targets the inhibition of cyclooxygenase-1 (COX-1) and the $\mathrm{P}_{2} \mathrm{Y}_{12}$ receptor in patients with acute coronary syndrome (ACS) and those treated with percutaneous coronary intervention (PCI). ${ }^{1}$ Despite proven clinical efficacy, the persistent ischemic event occurrence $(\approx 10 \%)$ suggests that dual antiplatelet therapy (DAPT) has reached a ceiling in its effect in attenuating thrombotic events and that some ischemic events are mediated by other pathways (non-COX-1 and non-P2 ${ }_{12}$ ). However, the addition of inhibitors of the platelet thrombin receptor $^{2}$ or coagulation factor ${ }^{3}$ to DAPT has not been clearly demonstrated to be effective in reducing ischemic event occurrence and has been associated with increased bleeding risk.

\section{Article p 2581}

Phosphodiesterases (PDEs) are potential targets for inhibition to attenuate adverse cardiovascular events in patients with coronary artery disease (CAD) ${ }^{4}$ The platelet cyclic adenosine 3',5'-monophosphate (cAMP) and cyclic guanosine 3',5'monophosphate (cGMP) stimulate protein kinases that are critical for regulating cellular function. PDEs convert cAMP and cGMP to inactive 5'-AMP and 5'-GMP, and influence downstream intracellular signaling. PDEs consist of 11 broad families (PDE1-PDE11), and their distribution and function differ according to species. ${ }^{4}$ Cilostazol is a dual inhibitor of PDE3 and adenosine reuptake that may have an important role in reducing ischemic events associated with CAD (Table 1). Cilostazol is a widely used selective and reversible inhibitor of PDE3, which is highly expressed in myocardial and vascular smooth muscle cells (VSMCs) and platelets. Cilostazol also inhibits adenosine reuptake into erythrocytes, endothelial cells, muscle cells, and platelets, thereby increasing interstitial and circulatory adenosine levels at clinically relevant concentrations $(\sim 3 \mu \mathrm{mol} / \mathrm{L}) .{ }^{5}$ Adenosine activates G-protein-coupled adenosine receptors, possesses a wide range of biological activities and influences cell survival through pre- and postconditioning processes. In platelets and VSMCs, the interaction of adenosine with $\mathrm{G}_{\mathrm{s}}$-coupled adenosine A2 receptors results in increased intracellular cAMP. Thus, cilostazol can increase the production and also inhibit the breakdown of cAMP in platelets and VSMCs. In contrast, adenosine mainly acts on $\mathrm{G}_{\mathrm{i}-\mathrm{c}}$ coupled adenosine A1 receptors in cardiac myocytes and reduces cAMP generation, which counteracts the cAMP elevation by PDE3 inhibition in the heart. This unique feature may contribute to the observed safety profile of cilostazol, and several studies have suggested a beneficial effect of cilostazol in arrhythmia prevention. ${ }^{6}$

In this issue of the Journal, Lee et al provide more evidence regarding the benefit of adding cilostazol to DAPT ["triple antiplatelet therapy" (TAPT)] in reducing post-PCI clinical events. ${ }^{7}$ In the primary analysis of the CILON-T (influence of CILostazol-based triple antiplatelet therapy ON ischemic complication after drug-eluting stent implantation) trial, ${ }^{8}$ TAPT did not show superiority in reducing the composite of adverse cardiovascular outcomes after drug-eluting stent implantation despite greater reduction in platelet reactivity assessed by the VerifyNow P2Y12 assay [ $\sim 5$ P2Y12 reaction units (PRU)] compared with DAPT. In the current post hoc analysis of the CILON-T trial, the investigators divided the cohort into 4 groups based on calcium-channel blocker (CCB) prescription and the type of antiplatelet therapy in a $2 \times 2$ factorial manner. A significantly greater level of platelet reactivity at discharge was observed in patients treated with CCB and DAPT together compared with DAPT alone (251 vs. $226 \mathrm{PRU}$; $\mathrm{P}=0.008$ ), but not in patients treated with TAPT (215 vs. 203 PRU; $\mathrm{P}=0.294$ ). The composite of cardiac death, non-fatal myocardial infarction and ischemic stroke at 6 months post-PCI was increased in patients treated with $\mathrm{CCB}$ in the DAPT group $(4.9 \%$ vs. $0.9 \%, \mathrm{P}=0.016)$, but not in the TAPT group (0\% vs. $1.8 \%$, $\mathrm{P}=0.346)$. $\mathrm{CCB}$ use without concomitant cilostazol use was a significant predictor of total thrombotic events, and the addition of cilostazol to DAPT was associated with reduced clinical event occurrence in patients taking $\mathrm{CCB}(\mathrm{P}=0.027$ for thrombotic events). This analysis is consistent with earlier findings that adding cilostazol to DAPT following PCI may be beneficial in high-risk patients. ${ }^{9}$

The current study findings are interesting and may be clinically relevant. The same investigators first reported that coadministration of the cytochrome $\mathrm{P} 450$ (CYP) 3A4 inhibitor may attenuate clopidogrel response and result in worsened clinical outcomes particularly in patients with the $C Y P 3 A 5 * 3 / * 3$ genotype..$^{10}$ The latter observation is supported by the findings of the current study. Further support for this observation comes from

The opinions expressed in this article are not necessarily those of the editors or of the Japanese Circulation Society.

Received September 25, 2011; accepted September 25, 2011; released online October 5, 2011

Sinai Center for Thrombosis Research, Baltimore, MD (Y.-H.J., U.S.T., K.P.B., P.A.G.), USA; and Division of Cardiology, Department of Internal Medicine, Gyeongsang National University Hospital, Jinju (Y.-H.J.), Korea

Mailing address: Paul A. Gurbel, MD, Sinai Center for Thrombosis Research, Cardiac Catheterization Laboratory, 2401 W. Belvedere Ave,

Baltimore, MD 21215, USA. E-mail: pgurbel@lifebridgehealth.org

ISSN-1346-9843 doi:10.1253/circj.CJ-11-1076

All rights are reserved to the Japanese Circulation Society. For permissions, please e-mail: cj@j-circ.or.jp 


\begin{tabular}{ll}
\hline Table 1. Pharmacokinetics, Pharmacodynamics and Mechanisms of Cilostazol ${ }^{4-6,18,22}$ & \\
Drug name \\
Chemical structure
\end{tabular}

O, definite; $\Delta$, proven by several studies; VSMC, vascular smooth muscle cell; cAMP, cyclic adenosine-monophosphate; $C Y P$, cytochrome P450; PDE, phosphodiesterase; NO, nitric oxide; HDL, high-density lipoprotein; PG, prostaglandin; SIRT, sirtuin.

\begin{tabular}{|c|c|c|c|c|c|c|}
\hline \multirow{2}{*}{ Parameter } & \multicolumn{2}{|r|}{ Cilostazol } & \multicolumn{2}{|c|}{ OPC-13015 } & \multicolumn{2}{|c|}{ OPC-13213 } \\
\hline & Before & After & Before & After & Before & After \\
\hline$t_{\max }(h)$ & $4 \pm 2$ & $5 \pm 3$ & $7 \pm 3$ & $13 \pm 9$ & $5 \pm 2$ & $46 \pm 3$ \\
\hline $\mathrm{C}_{\max }(\mu \mathrm{g} / \mathrm{L})$ & $621 \pm 172$ & $886 \pm 198(\uparrow 47 \%)$ & $129 \pm 39$ & $95 \pm 28(\downarrow 24 \%)$ & $61 \pm 20$ & $78 \pm 30(\uparrow 29 \%)$ \\
\hline $\mathrm{AUC}_{\mathrm{t}}(\mu \mathrm{g} / \mathrm{L} \cdot \mathrm{h})$ & $8,917 \pm 3,252$ & $16,770 \pm 9,475(\uparrow 87 \%)$ & $2,667 \pm 1,546$ & $2,828 \pm 2,165(\uparrow 8 \%)$ & $584 \pm 273$ & $1,280 \pm 484(\uparrow 141 \%)$ \\
\hline
\end{tabular}

$t_{\max }$, time to reach maximum plasma concentration; $\mathrm{C}_{\max }$, maximum plasma concentration; $\mathrm{AUC}_{\mathrm{t}}$, area under the plasma concentration-time curve $\mathrm{t}$.

a novel in vitro pharmacodynamic assay, which demonstrated that CYP3A4/5 isoenzymes play a significant role in both hepatic oxidation steps of clopidogrel. ${ }^{11}$ Among subjects homozygous for $C Y P 2 C 19 * 1$, Koreans displayed significantly lower CYP2C19 enzyme activity than Swedes $(\mathrm{P}<0.000001),{ }^{12}$ which may imply that CYP3A4/5 enzyme activity plays a more important role in clopidogrel metabolism among Koreans.

The addition of cilostazol in PCI-treated patients has been shown to reduce major cardiovascular events such as mortality, myocardial infarction and stent thrombosis. ${ }^{7,9}$ Although the vasodilatory and antiproliferative effects of cilostazol have been proposed to explain its clinical benefit, ${ }^{9,13}$ reduction in these ischemic events are unlikely to be explained by these mechanisms only. To date, several studies have demonstrated that adding cilostazol to DAPT significantly enhances platelet inhibition. ${ }^{14-16}$ Compared with double-dose clopidogrel therapy $(150 \mathrm{mg} /$ day $)$, TAPT was associated with a greater decrease in adenosine diphosphate (ADP)-induced platelet aggregation. ${ }^{14,15}$ The latter observation has been consistently observed in various high-risk clinical settings (ACS, diabetes, and complex $\mathrm{PCI}$ ), including the carriage of the $C Y P 2 C 19$ loss-of-function allele. ${ }^{15,16}$ In addition, Yang et $\mathrm{al}^{17}$ reported that platelets expressed the adenosine $\mathrm{A} 2 \mathrm{~b}$ receptor, which was upregulated under stress in vivo. Adenosine A2b receptor stimulation was associated with decreased expression of the P2Y 1 ADP receptor, implying that adenosine acts in platelets beyond its immediate influence on adenosine reuptake and platelet aggregation. This finding again supports the influence of adenosine on in vivo platelet aggregation. Taken together, it is important to note that the in vivo antithrombotic effect of cilostazol may not be completely reflected by the ex vivo platelet function test.

The interaction between cilostazol and CCB at the hepatic isoenzyme level cannot be overlooked. The decrease in platelet reactivity by the addition of cilostazol seems to differ between patients with and without CCB coadministration (at discharge: $\approx 37$ vs. 22 PRU, and at 6-month: $\approx 52$ vs. 41 PRU). ${ }^{7}$ Although cilostazol is a direct-acting drug, the 2 major metabolites of cilostazol, OPC-13015 (mainly produced by CYP3A4) and OPC-13213 (mainly produced by CYP3A5 and 2C19), account for approximately $50 \%$ of PDE3 inhibition. ${ }^{18}$ Single nucleotide polymorphisms (SNPs) of CYP2C19 and CYP3A5 thus may influence the pharmacokinetic and pharmacodynamic properties of cilostazol. ${ }^{16,19}$ Suri et al demonstrated that maximum plasma concentrations of cilostazol and OPC-13213 increased significantly, whereas OPC-13015 concentrations decreased significantly (all $\mathrm{P}<0.001$ ), following erythromycin coadministration in healthy volunteers receiving cilostazol (Table 2). ${ }^{20}$ It has been demonstrated that OPC-13015 is 3fold more potent in inhibiting platelet reactivity than cilostazol, whereas OPC-13213 is 3-fold less potent than cilostazol. ${ }^{18}$ Taking these findings together, CCB coadministration may moderately enhance the antiplatelet effect of cilostazol.

The current post hoc analysis by Lee et al has several limitations. A great body of data has demonstrated the reduced pharmacodynamic and clinical efficacy of clopidogrel in PCItreated patients carrying the $C Y P 2 C 19$ loss-of-function allele. ${ }^{21}$ 
Although demonstrating the relation of platelet reactivity to the occurrence of clinical events in patients receiving TAPT, the authors should have included the demographic variables, drug-drug interactions and SNPs as a combined variable. The investigators did not mention the time of blood sampling for platelet function measurement after the last-dose administration. In a healthy volunteer study using pharmacokinetic-pharmacodynamic model (a single dose of $100 \mathrm{mg}$ cilostazol), ${ }^{22}$ peak cilostazol concentration was achieved at $3.65 \mathrm{~h}$, but maximal platelet inhibition was at $6.05 \mathrm{~h}$ after cilostazol administration. The maximum pharmacodynamic effect was observed $\approx 8 \mathrm{~h}$ after clopidogrel loading. ${ }^{23}$ Because the pharmacodynamic effect of each drug in TAPT can vary, even during maintenance treatment, the specific sampling time may be important for reducing possible confounders. Finally, platelet reactivity was similar or increased after 6-month therapy compared with platelet reactivity measured at discharge. This is not in agreement with other pharmacodynamic studies in which a decrease in platelet reactivity ( $\approx 40 \mathrm{PRU}$ ) was reported. ${ }^{24-26}$

The current post hoc analysis has provided more insight regarding the potential benefits of adding cilostazol to DAPT, a strategy that may overcome the limitations of clopidogreldrug interactions, enhance platelet inhibition, and reduce the occurrence of post-PCI ischemic/thrombotic events without an increase in bleeding risk. However, we must keep in mind that an ex vivo platelet function test alone may not completely reflect the pleiotropic effects of cilostazol therapy.

\section{Acknowledgments}

This study was partly supported by grants from Institute of the Health Sciences, Gyeongsang National University, Jinju, South Korea, and Sinai Hospital of Baltimore, Baltimore, MD, USA.

\section{Disclosures}

Conflict of Interests: Dr Jeong received honoraria for lectures from SanofiAventis, Daiichi Sankyo Inc, and Otsuka. Dr Gurbel received research grants, honoraria, and consultant fees from Haemoscope, AstraZeneca, Schering-Plough/Merck, Medtronic, Lilly/Daiichi Sankyo Inc, SanofiAventis/Bristol Myers, Portola, Boston-Scientific, Bayer, Novartis, Accumetrics, Boehringer Ingelheim, and Johnson and Johnson.

\section{References}

1. Bonello L, Tantry US, Marcucci R, Blindt R, Angiolillo DJ, Becker $\mathrm{R}$, et al; Working Group on High On-Treatment Platelet Reactivity. Consensus and future directions on the definition of high on-treatment platelet reactivity to adenosine diphosphate. J Am Coll Cardiol 2010; 56: 919-933.

2. Trial to Assess the Effects of SCH 530348 in Preventing Heart Attack and Stroke in Patients With Acute Coronary Syndrome (TRA . CER) (StudyP04736AM2). http://clinicaltrials.gov/ct2/show/NCT0052794 3 ?term $=\mathrm{SCH}+530348 \&$ rank $=3$ (accessed September 20, 2011)

3. Alexander JH, Lopes RD, James S, Kilaru R, He Y, Mohan P, et al; APPRAISE-2 Investigators. Apixaban with antiplatelet therapy after acute coronary syndrome. N Engl J Med 2011; 365: 699-708.

4. Gresele P, Momi S, Falcinelli E. Anti-platelet therapy: Phosphodiesterase inhibitors. Br J Clin Pharmacol 2011; 72: 634-646.

5. Liu Y, Shakur Y, Kambayashi J. Phosphodiesterases as targets for intermittent claudication. Handb Exp Pharmacol 2011; 204: $211-$ 236.

6. Kanlop N, Chattipakorn S, Chattipakorn N. Effects of cilostazol in the heart. J Cardiovasc Med 2011; 12: 88-95.

7. Lee SP, Bae JW, Park KW, Rha SW, Bae JH, Suh JW, et al. Inhibitory interaction between calcium channel blocker and clopidogrel: Efficacy of cilostazol to overcome it. Circ J 2011; 75: 2581-2589.

8. Suh JW, Lee SP, Park KW, Lee HY, Kang HJ, Koo BK, et al. Multicenter randomized trial evaluating the efficacy of cilostazol on ischemic vascular complications after drug-eluting stent implantation for coronary heart disease: Results of the CILON-T (influence of CILostazol-based triple antiplatelet therapy $\mathrm{ON}$ ischemic complication after drug-eluting stenT implantation) trial. $J$ Am Coll Cardiol 2011; 57: 280-289.
9. Takagi H, Umemoto T. Benefit, rather than safety, of cilostazol for long-term mortality in patients undergoing percutaneous coronary intervention: A meta-analysis of randomized trials. Int J Cardiol 2011 Aug 16 [Epub ahead of print].

10. Suh JW, Koo BK, Zhang SY, Park KW, Cho JY, Jang IJ, et al. Increased risk of atherothrombotic events associated with cytochrome P450 3A5 polymorphism in patients taking clopidogrel. Can Med Assoc J 2006; 174: 1715-1722.

11. Abell LM, Liu EC. Dissecting the activation of thienopyridines by cytochrome P450's using a pharmacodynamic assay in vitro. J Pharmacol Exp Ther 2011 Aug 9 [Epub ahead of print].

12. Ramsjö M, Aklillu E, Bohman L, Ingelman-Sundberg M, Roh HK, Bertilsson L. CYP2C19 activity comparison between Swedes and Koreans: Effect of genotype, sex, oral contraceptive use, and smoking. Eur J Clin Pharmacol 2010; 66: 871-877.

13. Lee SW, Park SW, Kim YH, Yun SC, Park DW, Lee CW, et al; DECLARE-LONG II Study Investigators. A randomized, doubleblind, multicenter comparison study of triple antiplatelet therapy with dual antiplatelet therapy to reduce restenosis after drug-eluting stent implantation in long coronary lesions: Results from the DECLARELONG II (Drug-Eluting Stenting Followed by Cilostazol Treatment Reduces Late Restenosis in Patients with Long Coronary Lesions) trial. J Am Coll Cardiol 2011; 57: 1264-1270.

14. Jeong YH, Lee SW, Choi BR, Kim IS, Seo MK, Kwak CH, et al. Randomized comparison of adjunctive cilostazol versus high maintenance dose clopidogrel in patients with high post-treatment platelet reactivity: Results of the ACCEL-RESISTANCE (Adjunctive Cilostazol Versus High Maintenance Dose Clopidogrel in Patients With Clopidogrel Resistance) randomized study. J Am Coll Cardiol 2009; 53: $1101-1109$.

15. Kim IS, Jeong YH, Park Y, Park KS, Yun SE, Park JR, et al. Platelet inhibition by adjunctive cilostazol versus high maintenance-dose clopidogrel in patients with acute myocardial infarction according to cytochrome P450 2C19 genotype. JACC Cardiovasc Interv 2011; 4: 381-391.

16. Kim IS, Jeong YH, Park Y, Yun SE, Kwon TJ, Park JR, et al. Interaction analysis between genetic polymorphisms and pharmacodynamic effect in patients treated with adjunctive cilostazol to dual antiplatelet therapy: Results of the ACCEL-TRIPLE (Accelerated Platelet Inhibition by Triple Antiplatelet Therapy According to Gene Polymorphism) study. Br J Clin Pharmacol 2011 (in press).

17. Yang D, Chen H, Koupenova M, Carroll SH, Eliades A, Freedman $\mathrm{JE}$, et al. A new role for the $\mathrm{A} 2 \mathrm{~b}$ adenosine receptor in regulating platelet function. J Thromb Haemost 2010; 8: 817-827.

18. Hiratsuka M, Hinai Y, Sasaki T, Konno Y, Imagawa K, Ishikawa M, et al. Characterization of human cytochrome p450 enzymes involved in the metabolism of cilostazol. Drug Metab Dispos 2007; 35: 1730 1732.

19. Yoo HD, Park SA, Cho HY, Lee YB. Influence of CYP3A and CYP2C19 genetic polymorphisms on the pharmacokinetics of cilostazol in healthy subjects. Clin Pharmacol Ther 2009; 86: 281-284.

20. Suri A, Forbes WP, Bramer SL. Effects of CYP3A inhibition on the metabolism of cilostazol. Clin Pharmacokinet 1999; 37(Suppl 2): 61-68.

21. Oh IY, Park KW, Kang SH, Park JJ, Na SH, Kang HJ, et al. Association of cytochrome $\mathrm{P} 450$ 2C19*2 polymorphism with clopidogrel response variability and cardiovascular events in Koreans treated with drug-eluting stents. Heart 2011 Jun 23 [Epub ahead of print].

22. Woo SK, Kang WK, Kwon KI. Pharmacokinetic and pharmacodynamic modeling of the antiplatelet and cardiovascular effects of cilostazol in healthy humans. Clin Pharmacol Ther 2002; 71: 246-252.

23. Gurbel PA, Bliden KP, Butler K, Tantry US, Gesheff T, Wei C, et al. Randomized double-blind assessment of the ONSET and OFFSET of the antiplatelet effects of ticagrelor versus clopidogrel in patients with stable coronary artery disease: The ONSET/OFFSET study. Circulation 2009; 120: 2577-2585.

24. Gurbel PA, Bliden KP, Hiatt BL, O'Connor CM. Clopidogrel for coronary stenting: Response variability, drug resistance, and the effect of pretreatment platelet reactivity. Circulation 2003; 107: $2908-$ 2913.

25. Campo G, Parrinello G, Ferraresi P, Lunghi B, Tebaldi M, Miccoli $\mathrm{M}$, et al. Prospective evaluation of on-clopidogrel platelet reactivity over time in patients treated with percutaneous coronary intervention relationship with gene polymorphisms and clinical outcome. $J$ Am Coll Cardiol 2011; 57: 2474-2483.

26. Price MJ, Berger PB, Teirstein PS, Tanguay JF, Angiolillo DJ, Spriggs D, et al; GRAVITAS Investigators. Standard- vs high-dose clopidogrel based on platelet function testing after percutaneous coronary intervention: The GRAVITAS randomized trial. JAMA 2011; 305: 1097-1105. 